\title{
Os conselhos gestores municipais como instrumentos da democracia deliberativa no Brasil
}

\section{The management councils as instruments of deliberative democracy in Brazil}

\author{
Virgílio Cézar da Silva e Oliveira ${ }^{1}$ \\ José Roberto Pereira ${ }^{2}$ \\ Vânia A. R. de Oliveira ${ }^{3}$
}

\section{Resumo}

A gestão colegiada de políticas públicas exige novas relações, democráticas e dialógicas, entre sociedade e Estado. Requer, ainda, a construção de estruturas institucionais capazes de sustentá-la e o fortalecimento de espaços públicos não estatais. Em limites municipais, os conselhos gestores são agentes-chave desses processos. Com base em tais considerações, serão discutidas, neste ensaio, algumas premissas para que eles sejam, de fato, alicerces da democracia deliberativa - entendendo-a como método para formação de decisões coletivas por meio do diálogo entre indivíduos politicamente iguais. De modo a organizar a argumentação, as condições de efetividade foram distribuídas em três categorias. Na primeira estão concentrados elementos associados à organização formal dos conselhos. Na seguinte, aspectos referentes ao seu processo deliberativo. Pontos vinculados à conexão dos conselhos com segmentos sociais $\mathrm{e}$ poderes instituídos integram a última categoria.

Palavras-chave: Gestão municipal; políticas públicas; conselhos gestores; democracia deliberativa

\begin{abstract}
The collective management of public policies requires new relationships, both democratic and dialogical, between society and the State. It also requires the construction of institutional structures that are capable of sustaining it and of strengthening non-state public spaces. In municipal boundaries, the management councils are important players in these processes. From these considerations, this essay discusses some assumptions so that they are, in fact, foundations of deliberative democracy - understood as a method for formation of collective decisions by means of dialogue between politically equal individuals. In order to organize the argument, the conditions of effectiveness were divided into three categories. The first concentrates on elements related to the formal organization of councils. The following discusses aspects relating to their deliberative process. Issues concerning the connection of councils with social groups and local powers lie within the latter category.
\end{abstract}

Keywords: Municipal management, public policy, management councils, deliberative democracy

\section{Introdução}

A gestão colegiada de políticas públicas exige novas relações entre sociedade e Estado, pautadas pelo equilíbrio e pela dialogicidade. Requer, ainda, a consolidação de espaços públicos não estatais capazes de sustentá-la. Em âmbito municipal, os conselhos gestores são agentes-chave dessa construção político-institucional.

Os conselhos representam meios públicos de deliberação criados para promover a participação social. Suas funções abarcam a tomada de decisões sobre políticas locais e a regulação dos atos do governo, de modo a

Artigo submetido em março e aceito para publicação em julho de 2009.

${ }^{1}$ Doutor em Administração pelo Programa de Pós-Graduação em Administração da Universidade Federal de Lavras - PPGAD/UFLA. Professor na Universidade Federal de Alfenas, campus Varginha. Endereço: Av. Alfredo Braga de Carvalho, 303 - Bairro: Industrial JK - Varginha/Minas Gerais - Brasil - CEP: 37062-440. Email: virgilio@ unifal-mg.edu.br .

${ }^{2}$ Doutor em Sociologia pela Universidade de Brasília - UnB. Professor na Universidade Federal de Lavras. Endereço: Departamento de Administração e Economia, Campus Universitário - Centro. Lavras/Minas Gerais - Brasil - CEP: 37200-000. Email: jpereira@ufla.br .

${ }^{3}$ Doutoranda em Administração pelo Programa de Pós-Graduação em Administração da Universidade Federal de Lavras - PPGAD/UFLA. Endereço: Departamento de Administração e Economia, Campus Universitário - Centro. Lavras/Minas Gerais - Brasil - CEP: 37200-000. Email: vrezende9@yahoo.com.br. 
converter orçamentos em bens e serviços para a comunidade (AVRITZER, 2006). Na concepção de Gohn (2001), são novos meios de expressão e participação, dotados, em tese, de poder de transformação política. Sendo efetivamente representativos, propiciam o aprimoramento do formato das políticas setoriais.

Os conselhos podem contribuir para a democratização da gestão pública, a ampliação quantitativa e qualitativa da participação, a condução coletiva de políticas sociais, a responsabilização de governantes (accountability), o controle social pró-ativo e para o intercâmbio de informações entre população e poder local. Contudo, podem ser transformados em órgãos cartoriais (que apenas referendam as decisões do executivo), em mecanismos de legitimação do discurso governamental ou em estruturas formais (sem reuniões frequentes, programas de trabalho, representatividade social, vigor argumentativo, rotinas de capacitação e acesso aos poderes instituídos). A relação dos conselhos gestores com a democracia, mais precisamente com a democracia deliberativa local, será discutida a seguir.

Inicialmente, a democracia pode ser entendida como “(...) método (...) para constituição de governo e para formação das decisões (...) que abrangem toda a comunidade" (BOBBIO; MATTEUCCI; PASQUINO, 1991, p. 326). A via deliberativa constitui “(...) um modelo ou processo de deliberação política caracterizado por um conjunto de pressupostos teórico-normativos que incorporam a participação da sociedade civil na regulação da vida coletiva. Trata-se de um conceito que está fundamentalmente ancorado na idéia de que a legitimidade das decisões e ações políticas deriva da deliberação pública de coletividades de cidadãos livres e iguais" (LÜCHMANN, 2002, p. 19).

Nesse sentido, a construção coletiva de decisões por meio do diálogo entre indivíduos politicamente iguais representa a essência da democracia deliberativa, que pode ser exercida em diferentes contextos - público, público não governamental e privado - e níveis - nacional, regional e local. Em todos os casos, estruturas e regras de interação e pactuação devem ser concebidas. Além disso, desafios como a busca por consensos racionais, a pluralidade de visões e interesses e a participação em larga escala colocam em evidência aspectos como a argumentação pública (e não a simples votação), a simetria de forças entre sociedade e Estado, a delegação de poderes (representação) e o potencial de replicação desses arranjos institucionais.

Nas últimas duas décadas, principalmente em virtude do movimento constituinte, novos meios de reconhecimento e promoção da vontade coletiva foram formalizados. Destacam-se, entre estes, referendos, plebiscitos, ações civis públicas, leis de iniciativa popular, audiências públicas, fóruns temáticos, orçamentos participativos e conselhos gestores. Alguns, porém, não comportam a deliberação pública. Outros destinam-se a fins precisos e possuem vigência temporária.

Ao lado do orçamento participativo, os conselhos gestores estão sendo apontados como atores-chave da democracia deliberativa no Brasil (AVRITZER, 2000). Entretanto, seu índice de institucionalização é expressivamente maior. Dados de Ribeiro e Grazia (2003), referentes à gestão 1997-2000, atestam que 103 municípios conduziram orçamentos participativos no período. Paralelamente, a Pesquisa de Informações Básicas Municipais (IBGE, 2001) registra a presença de conselhos de saúde e assistência social em, respectivamente, $97,59 \%$ e $93,13 \%$ das cidades brasileiras. Órgãos voltados à infância e à juventude $(77,45 \%) \mathrm{e}$ à educação $(73,24 \%)$ também possuem inserções significativas.

Embora o alinhamento entre a democracia deliberativa (como corpo de ideias) e o conselho gestor (como formato institucional) seja considerável, algumas premissas devem ser satisfeitas para que ele possa dar, de fato, forma, estabilidade e continuidade político-administrativa à dialogicidade local. Tendo essas considerações como ponto de partida, objetiva-se, neste ensaio, identificar e discutir tais pressupostos. Para tanto, ele foi organizado em três partes. Na segunda parte, serão apresentadas a democracia e suas formas liberal, representativa, participativa e deliberativa. Na terceira, serão detalhadas as condições de efetividade dos conselhos como alicerces da democracia deliberativa local. As considerações finais sintetizam as conclusões do ensaio. 


\section{Os modelos de democracia}

A democracia possui mais virtudes que qualquer outra forma de governo. Nos dois últimos séculos, suas transformações promoveram a integração quantitativa e qualitativa dos cidadãos aos seus processos. $\mathrm{O}$ propósito deste tópico é discutir os modelos de democracia, tendo como base referenciais clássicos e contemporâneos. Antes, porém, sua origem e suas características serão apresentadas.

Identificar a origem da democracia não é uma tarefa simples. Como argumenta Dahl (2001), ela foi, provavelmente, inventada mais de uma vez em mais de um lugar. Contudo, as primeiras formas de governo que viabilizaram a participação cidadã foram instituídas na Grécia e em Roma por volta do ano 500 a.C. Os gregos cunharam o termo demokratia (demos: povo; e kratos: governar). As práticas de suas cidades-estado, especialmente Atenas, foram exemplos de governança coletiva. Já o sistema romano, a república (res: negócios; e publicus: do povo), limitava as grandes decisões à aristocracia. Depois de graves conflitos, a plebe foi integrada a esse processo. A queda da república romana eliminou os governos populares de grande amplitude por cerca de mil anos. No século XII eles ressurgiram na Itália. O caráter representativo da democracia, fundamental à sua vigência contemporânea, desenvolveu-se séculos mais tarde ao norte do Mediterrâneo.

Como argumenta Touraine (1996), a democracia tende a ser conceituada de duas maneiras. Para alguns, ela busca dar forma à soberania popular. Para outros, ela pretende garantir a liberdade do debate político. No primeiro caso, ela é definida por sua substância, e no segundo, por seus procedimentos. Em ambos, seu valor fundamental é a liberdade individual:

Enquanto a sociedade civil - isto é, de fato, o sistema econômico - é dominada pela desigualdade e pelos conflitos de interesses, a sociedade política deve ser o espaço da igualdade; portanto, a democracia tem como objetivo principal garantir a igualdade não só de direitos, mas também das oportunidades e limitar o quanto possivel a desigualdade dos recursos. (TOURAINE, 1996, p. 160)

A perspectiva social de Touraine (1996) pode ser complementada pela visão política de Dahl (2001), segundo a qual, no cerne dos sistemas democráticos, está a noção de que todos devem ser tratados como igualmente qualificados para participar das decisões. Assim, as democracias de fato devem resguardar: a participação efetiva, a igualdade do voto, o entendimento das questões comuns, o controle coletivo dos processos democráticos e a inclusão dos adultos.

O pensamento destes autores também é sinérgico na seleção das razões que tornam a democracia desejável. Para Touraine (1996), ela requer o reconhecimento do outro, a integração das diferenças (desaparecimento do uno) e a ação individual livre. Segundo Dahl (2001), as democracias impedem o governo de autocratas, garantem aos cidadãos direitos essenciais, asseguram liberdades mais amplas do que qualquer outro regime, ajudam a preservar interesses pessoais, proporcionam a máxima oportunidade de autodeterminação, promovem o exercício da responsabilidade moral, propiciam o desenvolvimento humano, geram um alto grau de igualdade política, não empreendem guerras entre si e, finalmente, promovem a prosperidade mais intensamente do que outras formas de governo.

As democracias contemporâneas são regimes políticos de larga escala que demandam funcionários eleitos, eleições justas e frequentes, liberdade de expressão, fontes diversificadas de informação, autonomia associativa e cidadania inclusiva (DAHL, 2001). O reconhecimento desses pressupostos é fruto do amadurecimento da democracia. Em tal processo, seus méritos, limitações e riscos tornaram-se mais claros.

\section{Democracia liberal}

O liberalismo, como termo político, admite múltiplas acepções. Entretanto, ele nunca esteve apartado de sua origem latina líber, isto é, livre. Dessa forma, "liberalismo" designa o ponto de vista daqueles cuja principal preocupação política é adquirir ou preservar algum grau de liberdade dentro do controle exercido pelo Estado ou por qualquer outra instituição que possa ser considerada contrária à liberdade (SILVA; MIRANDA NETTO, 1987). 
Sob a forma de democracia liberal, o liberalismo buscou proteger os cidadãos das arbitrariedades do Estado absoluto, fomentando a liberdade e a expansão das capacidades humanas (MACPHERSON, 1978). Nesse sentido, Bobbio (1994) afirma que o liberalismo vincula-se a uma concepção de Estado com funções e poderes limitados. Seu princípio filosófico é a doutrina dos direitos do homem, concebida pela escola do direito natural (jusnaturalismo), segundo a qual todos têm, por natureza, direito à vida, à liberdade, à segurança e à felicidade. Cabe ao Estado respeitá-los e protegê-los.

A restrição da autonomia e da responsabilidade estatal consolidou, respectivamente, o Estado de direito e o Estado mínimo. No primeiro os direitos naturais são resguardados juridicamente e o poder público é regulado por normas universais. Prioriza-se, portanto, o governo das leis em detrimento do governo dos homens. $\mathrm{O}$ segundo busca interferir minimamente em processos econômicos e sociais (BOBBIO, 1994).

A democracia liberal será discutida nos parágrafos seguintes, evidenciando: a) o estudo pioneiro de Tocqueville sobre a democracia norte-americana e seu grande risco: o despotismo da maioria e b) as formas protetora, desenvolvimentista e elitista-pluralista que ela assumiu nos séculos XIX e XX.

Ao aportar em maio de 1831 nos Estados Unidos, o francês Alexis de Tocqueville viu-se diante de uma nação particular, na qual as diferenças sociais, culturais e políticas eram tênues. Como detalha Aron (2002), seu foco voltou-se para a compreensão do caráter liberal e democrático dessa sociedade. Tal combinação era especialmente intrigante para o pensador devido à sua origem aristocrática. Na base desse sistema social, Tocqueville identificou os valores puritanos, favoráveis à igualdade e à liberdade. Paralelamente, destacou que a democracia estadunidense serviu-se da educação política do povo e de sua rigorosa obediência às leis, antídotos contra as lutas entre facções que, no passado, assolaram o país.

A conexão estabelecida por Tocqueville (1969) entre as esferas religiosa e política admitia que, na primeira, tudo estava previsto e ordenado; enquanto, na segunda, tudo era objeto de disputa e negociação. De um lado, predominava a obediência; do outro, a independência. Essa concepção da dinâmica política foi importante para consolidar a noção de soberania do povo, que orientou todo o sistema de governo estadunidense. Segundo ela, cada cidadão deveria dispor da mesma parcela de poder e participar da condução do Estado. A gestão autônoma das localidades (townships), principalmente na Nova Inglaterra, foi o meio encontrado para viabilizar tal tarefa.

Declarando especial interesse pelas consequências políticas dessa descentralização, o pensador reconheceu a relevância da ação coletiva privada que, sem se anular diante da autoridade local, empenhava-se em solucionar problemas comunitários e em conduzir empreendimentos diversos.

A propensão à associação dos cidadãos estadunidenses mereceu considerações específicas de Tocqueville. Esse fato é justificável por sua capacidade de inibir a principal ameaça à democracia em sociedades planificadas: o despotismo da maioria. A análise do despotismo da maioria exigirá o detalhamento das concepções de democracia e liberdade do autor.

Como detalha Aron (2002), o conceito de democracia segundo Tocqueville, ainda que não explicitado em seu texto, vincula-se à igualdade. Em regimes democráticos, qualquer distinção hereditária de condições deveria ser abolida. Os indivíduos, que não eram intelectualmente ou economicamente iguais, deveriam sê-lo politicamente. Sociedades dessa natureza deveriam apresentar como objetivo central a extensão do bem-estar para o maior número possível de pessoas.

Contudo, a planificação social despertava em Tocqueville temores relacionados à manutenção da liberdade. Nas monarquias, esse direito era preservado, em grande medida, pela desigualdade, pois cada classe reconhecia sua posição, seus deveres e privilégios na escala social. Alternativamente, a liberdade moderna deveria basearse na igualdade, salvaguardada por instituições autônomas.

Para Tocqueville, a liberdade, sedimentada em múltiplos e representativos centros de decisão, materializava-se na ausência de arbitrariedades e na universalidade das leis. Suficientemente forte para desencorajar novos tiranos, ela encontraria no poder do homem comum e no despotismo da maioria suas grandes ameaças: 
Tomada coletivamente, a maioria é apenas um indivíduo cujas opiniões e, freqüentemente, interesses são opostos aos de outro indivíduo, intitulado minoria. Se se admite que um homem possuindo poder absoluto pode usar, erradamente, esse poder fazendo mal a seus adversários, por que não será a maioria passível da mesma censura? Os homens não mudam seu caráter unindo-se uns aos outros; nem sua paciência diante de obstáculos aumenta com sua força. De minha parte não posso acreditar nisso; o poder de tudo fazer, que recuso a um de meus iguais, nunca o concederei a qualquer número deles. (TOCQUEVILLE, 1969, p. 133)

Embora reconheça a necessidade de um poder social superior, Tocqueville crê que este constitui uma ameaça à liberdade quando não encontra obstáculos capazes de moderá-lo. Assim, os riscos associados às instituições democráticas norte-americanas são produto de sua 'força irresistível' e não de suas debilidades.

Prosseguindo com a discussão da democracia liberal, nota-se que ela inspirou, nos séculos XIX e XX, três grandes orientações: a democracia protetora, a democracia desenvolvimentista e a democracia de equilíbrio ou elitista-pluralista. Subjacente a esses modelos há um ideal de indivíduo (e, consequentemente, de sociedade) e um construto teórico capaz de legitimá-los (MACPHERSON, 1978).

A democracia protetora foi construída em bases utilitaristas, por meio das quais os indivíduos perseguiam a maximização do prazer. Como o único meio capaz de exprimi-lo era o dinheiro, todos deveriam buscar a ampliação de sua riqueza e de seu poder. Transferida para o campo político, essa lógica iria determinar a submissão dos cidadãos pelos governantes. As razões que justificavam sistemas políticos democráticos e liberais eram, portanto, de natureza defensiva. Seus mecanismos de proteção social foram, individualmente, o voto (masculino e condicionado à propriedade), e coletivamente, a substituição dos governantes. Seus grandes ideólogos foram Jeremias Bentham e James Mill.

Na metade do século XIX, surgiu uma concepção de homem distinta do ser apropriador. Para alguns pensadores, como Stuart Mill, os indivíduos seriam capazes de desenvolver suas capacidades. Poderiam, ainda, desfrutá-las e experimentar formas qualitativamente diferentes de prazer. A boa sociedade seria aquela que permitisse e incentivasse tais processos. Nesse sentido, a universalização do sufrágio masculino foi reivindicada para que os cidadãos pudessem evoluir (daí a adjetivação desenvolvimentista) por meio da participação. Esse fato, contudo, poderia eternizar no poder as classes mais numerosas: trabalhadores (em nações industriais) e camponeses (em sociedades agrárias). A ação moderadora do sistema partidário deveria afastar esse risco, conciliando desigualdades sociais e voto masculino irrestrito.

As discussões relativas à democracia liberal, ainda de caráter desenvolvimentista, assumiram novos contornos nas primeiras décadas do século XX. De um lado, o idealismo foi intensificado e a crença de que as diferenças sociais poderiam ser equilibradas ganhou força. A função do Estado democrático seria, portanto, exprimir e executar a vontade geral de cidadãos e não de seres maximizadores. Em contrapartida, teóricos mais pragmáticos, como John Dewey, desconfiavam da máquina política como promotora de mudanças sociais. Sua fonte deveria ser o humanismo democrático, valor a ser introduzido nas esferas cultural, política e econômica.

O terceiro modelo, denominado por Macpherson (1978) 'democracia de equilíbrio', também é conhecido como elitista-pluralista. 'Elitista', pois, concebe a escolha dos governantes como uma competição entre elites políticas previamente selecionadas por si mesmas. Nessa vertente, os eleitores não devem se ocupar com problemas políticos, mas, somente, indicar aqueles que irão propor e conduzir as soluções. 'Pluralista', visto que parte de uma sociedade heterogênea, formada por indivíduos com diferentes interesses e filiações. A adjetivação 'de equilíbrio', por fim, refere-se à sua busca por um ponto ótimo entre a oferta e a procura por bens públicos (demandas cidadãs frente ao governo). Um dos principais artífices desse modelo foi Joseph Schumpeter.

A democracia de equilíbrio não preservou o conteúdo moral da democracia desenvolvimentista. Seu propósito era viabilizar os desejos dos indivíduos e, não, contribuir para a sua evolução. Na concepção elitista-pluralista, a lógica da política aproximou-se da lógica do mercado: os eleitores agiriam como consumidores; e os políticos, como ofertantes. Ambos seriam maximizadores racionais atuando em condições de livre concorrência 
política. Contudo, a possibilidade de um eleitor consumidor tornar-se um político ofertante é, na maioria dos casos, limitada pela desigualdade de recursos. Mesmo entre a classe política não prevalece o equilíbrio de condições. Como resultado, oligopólios políticos podem ser formados e o sistema perderá sua capacidade de contemplar demandas específicas (MACPHERSON, 1978).

As considerações contemporâneas de Bellamy (1994) sobre a democracia liberal não devem ser ignoradas. Para este autor, na sociedade moderna, a liberdade individual não pode ser garantida a não ser pela limitação do poder central no que tange à normatização da vida social. Nesse sentido, ele propõe a descentralização do poder por meio de instituições democráticas (agências) que proporcionem, ao cidadão, condições de defesa quando coagido.

\section{Democracia representativa}

As democracias de larga escala demandam alguma forma de delegação. Assim, às características das democracias liberal, participativa e deliberativa aplicam-se as vantagens e as limitações da representação. Na primeira metade do século XX, o regime político elitista dos Estados-nação passou a ser viabilizado pelo sufrágio universal (BRESSER PEREIRA, 2005). Desde então, segundo Hirst (1992), a democracia representativa passou por três momentos. No primeiro. foi ameaçada, como instituição, pelo facismo e pelo stalinismo; e como corpo de idéias, pelo facismo e pelo marxismo-leninismo. No segundo, durante a década de 1960, ela foi rechaçada por forças estudantis em nome da democracia participativa direta. Finalmente, após duas décadas, ela se viu incontestada e fortalecida na maioria dos países, inclusive na Europa oriental.

Hirst (1992), analisando prioritariamente a realidade britânica, argumenta que a democracia representativa possui dois grandes problemas: o baixo envolvimento popular nas decisões políticas e a limitada prestação de contas dos governos aos cidadãos. Se, por um lado, as democracias de massa legitimam a autoridade política; por outro, não favorecem o protagonismo popular e o controle social.

Como desdobramentos desses aspectos destacam-se: a) a tendência de a democracia representativa se transformar em um despotismo eletivo, no qual os políticos exploram ao máximo as possibilidades oferecidas pela administração para alcançar objetivos particulares; b) a emergência, ao lado do despotismo político, do poder não fiscalizável da burocracia; c) a limitada disseminação de informações politicamente relevantes; e d) a difícil condução de mudanças políticas devido à resistência administrativa e à pluralidade de visões e interesses intragoverno.

Nas democracias de massa, como a representação não pode ser suplantada, deve ser suplementada. Nesse sentido, Hirst (1992) defende que a apatia social e a hegemonia dos grandes partidos podem ser reduzidas por meio da representação de interesses, da descentralização estatal e da delegação de responsabilidades à sociedade civil.

No primeiro caso, a representação organizada de interesses fortaleceria a democracia ampliando a influência popular sobre os governos. A aproximação entre sociedade e Estado poderia ser estimulada pela consolidação de redes público-privadas de proposição e persuasão política.

A centralização estatal dificulta a prestação de contas ao cidadão ao concentrar informações e poder administrativo e ao impor barreiras à interferência social nas decisões políticas. A reversão desse quadro, denominada pelo autor "pluralização do Estado", consiste em conferir autonomia às autoridades funcionais locais, diminuindo o papel do governo central e o volume de questões em jogo nas eleições nacionais.

A delegação de funções à sociedade civil organizada, ou 'socialismo associativo', complementa o processo anterior transferindo tarefas de organização social e econômica para associações autogovernadas e voluntárias de cidadãos. Curiosamente, os princípios da 'terapia' de Hirst (1992) e as características da organização sociopolítica estadunidense no século XIX, descritas por Tocqueville (1969), apresentam grande semelhança. 


\section{Democracia participativa}

Na década de 1960, a democracia participativa emergiu internacionalmente como bandeira dos movimentos estudantis da Nova Esquerda. Nos anos seguintes, ganhou espaço com a insatisfação da classe trabalhadora, ecoando em alguns governos que empreenderam programas baseados na participação popular.

Escrevendo sobre as possibilidades da democracia participativa, Macpherson (1978) afirmou que, para alcançála, os cidadãos deveriam abandonar a condição de consumidores políticos (alinhada à via elitista-pluralista), assumindo o desenvolvimento de suas capacidades. Essa nova orientação traria em si um senso de coletividade que a democracia liberal elitista-pluralista ignorava. Outra premissa desse modelo democrático seria o nivelamento das diferenças econômicas e sociais, uma vez que a desigualdade amplia a necessidade de um sistema partidário não participativo capaz de garantir a coesão social.

Ainda que essas duas condições ideais estivessem - e ainda estão - longe de se concretizarem, a consciência quanto aos custos da apatia política era, para Macpherson (1978), crescente. Desse modo, a promessa da democracia participativa tornava-se continuamente mais próxima. Entretanto, o efetivo envolvimento dos cidadãos requer, entre outros pontos, esforços de engenharia institucional. Nesse sentido, a democracia participativa, em sua configuração mais simples, deveria consolidar um sistema piramidal, com democracia direta na base e democracia por representação em cada nível ascendente. Assim, discussões face a face poderiam ser realizadas em comunidades e organizações e conduzidas a fóruns superiores. Partidos políticos em concorrência também poderiam empregar tal estrutura.

Distante quase três décadas da análise de Macpherson (1978), Bresser Pereira (2005) reconhece a vigência da democracia participativa, principalmente na Europa, pois: a) a opinião pública tornou-se um meio eficaz de responsabilização política (accountability); b) o Estado social-democrático comprometeu-se com a proteção dos direitos sociais; e c) as organizações da sociedade civil tornaram-se interlocutores políticos legítimos e influentes. Paralelamente, a participação democrática tem sido potencializada pela emergência de cidadãos dotados de virtudes públicas. Ainda que motivados por objetivos particulares, eles demonstram senso nacionalista, comprometimento com o interesse público, visão crítica do processo político e confiança nas instituições democráticas.

Mesmo que essa tendência não produza uma nova doutrina do interesse bem compreendido, em que o benefício público legitima sacrifícios privados frequentes (TOCQUEVILLE, 1969), suas possibilidades são vastas. Entre elas, destaca-se o caráter pedagógico da participação. Assim, por meio de processos coletivos de conscientização e capacitação, a cidadania pode ser fortalecida e ciclos de subordinação e injustiça social interrompidos (PATEMAN, 1992).

Na visão de Bresser Pereira (2005), a forma de democracia que desponta nas sociedades avançadas é de natureza essencialmente participativa. Desse modo, ela supera os tipos elitistas de representação sem, contudo, concretizar o ideal deliberativo. A vertente participativa:

Satisfaz-se com as condições de que o debate envolva uma participação substancial das organizações da sociedade civil e siga regras mínimas de ação comunicativa, em especial a do respeito mútuo pelos argumentos que justificam cada posição. As decisões serão tomadas, em última estância, pelos parlamentares eleitos no contexto de um sistema representativo, mas cada decisão importante será precedida de um vivo e amplo debate público. Tal debate influenciará a agenda e o enquadramento das principais alternativas para cada decisão. Em alguns casos os argumentos apresentados serão suficientemente fortes para convencer a outra parte. Em outros uma nova alternativa surgida do debate poderá satisfazer os grupos conflitantes, superando-se assim o conflito. Na maior parte dos casos, porém, o compromisso continuará sendo necessário, e o voto da maioria acabará decidindo o assunto. (BRESSER PEREIRA, 2005, p. 82)

Baseando-se nas considerações de Elster e Habermas, Lüchmann (2002) afirma que a democracia participativa tende a reverter a prioridade política, enfatizando sua face educativa em detrimento da decisória. Os benefícios da primeira devem ser percebidos como subprodutos e não como fins. Paralelamente, ao depender das 
qualidades de cidadãos orientados para o interesse público, ela apresenta um caráter homogêneo e virtuoso não compatível com a realidade.

O debate sobre a participação democrática tem evoluído com o conceito de democracia deliberativa. Sua natureza idealista, antes de tornar sem efeito os esforços políticos e acadêmicos que buscam consolidá-la, redefine o desafio democrático e contribui para o seu aperfeiçoamento. O tópico seguinte irá detalhar a via deliberativa, discutindo sua origem, sua operacionalização e o argumento de seus críticos.

\section{Democracia deliberativa}

Na teoria democrática, a noção de deliberação pública apresentou diferenças entre o início e o final do século XX. A transição de um enfoque decisório (ou decisionístico) para uma concepção argumentativa - analisada em detalhes por Avritzer (2000) - estabeleceu as condições para a emergência da democracia deliberativa.

Até a metade do século XX, os ideólogos da democracia mostravam-se céticos em relação às possibilidades da argumentação. Três aspectos justificavam esse posicionamento. Inicialmente, a importância do debate político foi subestimada pela crença de que o pluralismo impedia o consenso social. Paralelamente, a participação popular foi considerada contraproducente para a gestão do Estado, pois reduzia a eficiência e a racionalidade de seus processos. Finalmente, a discussão democrática foi limitada pela percepção do processo eleitoral como uma simples aferição de preferências individuais formadas previamente.

Tais concepções perderam seu vigor nas últimas décadas do século XX devido, principalmente, às proposições de John Rawls e Jürgen Habermas. Ao supor que os indivíduos não apresentam preferências pré-estabelecidas, Rawls rompe com a lógica decisionística. Em sua visão, discordâncias razoáveis poderiam ser úteis à política, balanceando as diversas posições. Entretanto, para que isso ocorresse, procedimentos de suporte à argumentação deveriam ser consolidados. Os esforços do outro pensador voltaram-se para esse propósito.

Em Mudança Estrutural da Esfera Pública, Habermas preocupou-se com a formação de um espaço de interação diferenciado do Estado, no qual os indivíduos pudessem debater questões políticas e delinear estratégias capazes de tornar o poder público sensível às suas deliberações. Nesse local, a autoridade do melhor argumento deveria prevalecer sobre a hierarquia social. Ao publicar A Teoria da Ação Comunicativa, Habermas estabeleceu as noções de mundo social reflexivamente adquirido e de ação intersubjetiva voltada ao consenso comunicativo. Por meio delas, este autor buscou reincorporar a argumentação aos campos social e político.

O nexo entre a teoria de Habermas e a política emerge da percepção de que a legitimidade desta não é, exclusivamente, produto da vontade da maioria. Antes, ela depende de processos deliberativos capazes de promover a participação racional de cidadãos interessados ou afetados por decisões públicas. Orientada pela construção teórica de Habermas, Lüchmann (2002) define a democracia deliberativa como:

(...) um modelo ou processo de deliberação política caracterizado por um conjunto de pressupostos teórico-normativos que incorporam a participação da sociedade civil na regulação da vida coletiva. Trata-se de um conceito que está fundamentalmente ancorado na idéia de que a legitimidade das decisões e ações políticas deriva da deliberação pública de coletividades de cidadãos livres e iguais. Constitui-se, portanto, em uma alternativa crítica às teorias 'realistas' da democracia que, a exemplo do 'elitismo democrático', enfatizam o caráter privado e instrumental da política. (LÜCHMANN, 2002, p. 19)

Como salienta Avritzer (2000), um questionamento dirigido à via deliberativa de Habermas refere-se à relação entre a esfera pública e o sistema político-administrativo. Na obra Entre Fatos e Normas, o filósofo afirmou que, nos limites da esfera pública, os atores não poderiam adquirir poder político, mas, apenas, influenciar seus detentores. Assim, apesar de a teoria habermasiana redefinir as bases de legitimação da ação política, não propôs arranjos institucionais capazes de materializar a democracia deliberativa. 
O debate sobre a operacionalização desse modelo democrático tem evoluído com as contribuições de diversos autores. Contudo, as proposições de Joshua Cohen e James Bohman são dignas de nota. Suas idéias, sistematizadas por Faria (2000), serão apresentadas, sucintamente, a seguir.

Para Cohen, a visão habermasiana de que a sociedade é capaz de identificar demandas alheias à agenda pública, de propor soluções e de influenciar o sistema político promove rompimentos meramente ocasionais na rotina do poder. Democracias de fato e, consequentemente, governos legítimos, devem ser viabilizados por poliarquias diretamente deliberativas. O propósito desse arranjo é promover a solução de problemas diretamente pelos cidadãos. Na base desse processo está a deliberação, conduzida em arenas abertas aos usuários de serviços públicos. Estes, quando argumentam, devem orientar-se por casos análogos registrados em outras jurisdições. Idealmente, a poliarquia diretamente deliberativa pode favorecer o autogoverno, o aprendizado local e a responsabilização política.

O trabalho de Bohman alinha-se ao de Habermas e Cohen ao discutir como as instituições públicas (agências burocrático-administrativas) podem ser democratizadas pela deliberação cidadã. Essa atividade expressa um intercâmbio de razões voltado à solução de problemas que não são equacionáveis sem a coordenação de esforços. As maiorias deliberativas devem responder por sua operacionalização. Para Bohman, a cooperação e a legitimidade das decisões não são ameaçadas pela regra da maioria. Ao contrário, a participação justa e inclusiva das partes concede à minoria meios para interferir nas deliberações e para mudar as regras do processo decisório. A soberania das maiorias deliberativas deve ser assegurada pela interação entre as instituições públicas e o sistema político. Para tanto, as primeiras devem constituir esferas públicas próprias.

Analisando o descompasso entre o ideal argumentativo e a realidade contemporânea, Vittulo (2000) reuniu as principais críticas à democracia deliberativa. Inicialmente, seus defensores buscam sua forma desejável, esclarecendo pouco sobre como ela pode operar realmente. Além disso, sua institucionalização tende a gerar conflitos entre os planos normativo e prático. Os requisitos para a democracia deliberativa compreendem: o debate de todos os interessados em um assunto, a igualdade política substancial, o intercâmbio livre de informações (capaz de nivelar conhecimentos) e, ainda, a imparcialidade dos métodos de decisão e determinação de pautas. A estas condições somam-se outras como: a adequada dimensão dos grupos, a inexistência de minorias isoladas, o caráter mutável da composição dos corpos majoritário e minoritário e, por fim, a não interferência do desequilíbrio de recursos na conduta deliberativa.

Mesmo em sociedades modernas, o atendimento a essas premissas está longe de acontecer. A assimetria de oportunidades (culturais, políticas etc.) e capacidades (econômicas, cognitivas, discursivas etc.) estabelece censuras e autocensuras que inviabilizam a participação equânime. Assim, a democracia deliberativa deve ser precedida por mudanças radicais como: a reorganização do campo econômico, a construção de instituições sensíveis às demandas do cidadão comum e a universalização de oportunidades educacionais e políticas.

\section{Democracia deliberativa e conselhos gestores: condições de efetividade}

Neste tópico serão discutidas condições importantes para consolidar os conselhos gestores como instrumentos da democracia deliberativa local. De modo a tornar mais clara essa exposição, os argumentos foram divididos em três grupos. O primeiro concentrará elementos relativos à organização formal dos órgãos: procedimentos internos e desenho institucional. O segundo reunirá aspectos ligados à sua dinâmica deliberativa, abarcando a participação e rotinas de argumentação e pactuação. Questões referentes ao elo institucional dos conselhos com segmentos sociais e poderes instituídos integram a última categoria.

\section{Democracia deliberativa e conselhos: condições formais de efetividade}

Tendo em mente a essência da democracia deliberativa, isto é, considerando-a um método para formação de decisões coletivas por meio do diálogo entre indivíduos politicamente iguais, duas noções mencionadas serão recorrentes no texto: dialogicidade e igualdade política. Diversos elementos formais dos conselhos buscam resguardar tais princípios. 
Nesse sentido, o primeiro ponto a ser destacado é a natureza dos órgãos: deliberativa, consultiva ou operativa. Os conselhos deliberativos devem integrar-se às rotinas públicas, condicionando sua gestão. De outro modo, os pareceres de um conselho consultivo podem, ou não, ser acatados pelos gestores locais. Por fim, o caráter essencialmente fiscalizador dos conselhos operativos, reconhecido por Noronha (2000), distancia a representação social da concepção e da gestão de políticas sociais. Programas de distribuição de alimentos e de transferência de recursos - para o ensino fundamental, para merenda escolar etc. - são monitorados por esses órgãos. Percebe-se, portanto, que apenas as decisões dos conselhos deliberativos afetam obrigatoriamente e integralmente processos públicos.

Além desse aspecto, o modo como algumas rotinas são organizadas nos conselhos opera para que eles sejam intrinsecamente democráticos e independentes do poder local, reduzindo assimetrias e constrangimentos. Cumpre discutir, nesse momento, o equilíbrio de poder nos órgãos, seus mandatos, seus processos pedagógicos e seu acesso a recursos administrativos e financeiros.

A igualdade numérica, capaz de assegurar a simetria decisória entre população e governo, não extingue os desafios da paridade, da representatividade e da autonomia. A paridade deve servir-se de condições equânimes de acesso, por parte dos conselheiros, à informação - insumo argumentativo essencial. Em diversos casos, a paridade formal é distorcida pela posição privilegiada da designação governamental, que dispõe de tempo e meios para articular-se (TEIXEIRA, 2000a).

A representatividade, por seu turno, associa-se à revogabilidade dos mandatos e à seleção de conselheiros. A interrupção de mandatos é um ato extremo, determinado pelos níveis de assiduidade, compromisso e legitimidade dos conselheiros. Se negligenciada, o vigor deliberativo dos órgãos pode ser comprometido. Prosseguindo, os processos de eleição (designação social) e indicação (designação governamental) de conselheiros devem ser criteriosos, de modo a agregar aos órgãos indivíduos dotados de vínculos comunitários, virtudes públicas e capacidades analítico-discursivas.

Por fim, a distribuição interna de funções deve resguardar e refletir a autonomia dos conselhos, negando práticas como: submissão de listas tríplices ao prefeito municipal para seleção de nomes e designações compulsórias, em que cargos específicos na gestão local garantem posições-chave nos conselhos.

A autonomia deliberativa dos conselhos também depende de meios físicos, gerenciais e financeiros. Os primeiros materializam-se em espaços, móveis e equipamentos disponíveis para reuniões, encontros de comissões de trabalho, capacitações coletivas, levantamento e distribuição de informações. Complementamnos, em certos casos, funcionários e assessorias técnicas. O último item requer dotações orçamentárias específicas e controle sobre fundos públicos. A indisponibilidade de recursos agrava a dependência dos conselhos em relação ao executivo e desencadeia constrangimentos e protelações.

A ação efetiva dos conselhos depende de seus processos pedagógicos. Entretanto, iniciativas sistemáticas de capacitação e 'empoderamento' não são facilmente observáveis. Conteúdos referentes aos ritos deliberativos, aos limites e às possibilidades dos próprios conselhos, aos dilemas históricos de cada segmento, à legislação pertinente e aos processos de formulação, gestão e controle de políticas sociais devem ser transmitidos. Ademais, a troca de informações e experiências entre conselhos e conselheiros deve ser estimulada. Ações de caráter intersetorial podem ser viabilizadas por meio desse diálogo.

\section{Democracia deliberativa e conselhos: condições substantivas de efetividade}

No que se refere ao processo deliberativo dos conselhos, ao menos três conjuntos de fatores interferem em sua condição de instrumento da democracia deliberativa local. São estes: a) a garantia de procedimentos democráticos de argumentação e deliberação; b) a promoção da cidadania deliberativa; e c) a compreensão das nuanças da participação e o estímulo à sua forma política.

A consolidação de processos democráticos de deliberação é condição essencial para que censuras e autocensuras sejam minimizadas. Nesse sentido, o respeito à fala e ao posicionamento das partes deve estar em primeiro plano. Além disso, saberes e discursos especializados, técnicos ou burocráticos, não devem ser 
transformados em instrumentos de poder ou exclusão. Devem ser externados com clareza, didaticamente, para que possam fundamentar consensos racionais.

Outro aspecto digno de atenção, que interfere no conteúdo dos debates, é o controle das pautas de reunião. A seleção de assuntos a tratar pode ser usada estrategicamente, principalmente pelo poder local, para desviar o foco de temas importantes, postergar decisões ou, ainda, induzir pareceres emergenciais e, portanto, pouco criteriosos. As pautas devem ser abertas às proposições dos conselheiros e das organizações sociais. Devem ser dinâmicas de modo a incorporar temas relevantes que surgem durante as reuniões.

Os múltiplos atores e as diversas visões que interagem nos conselhos não podem fechar-se ao diálogo. Ao contrário, devem influenciar-se mutuamente e cooperar para que argumentos e soluções coerentes sejam viabilizados. A razão, portanto, não deve ser considerada antecipadamente, como um atributo dos sujeitos (ou da maioria). Deve emergir de discursos e argumentos, como um construto coletivo, legítimo. A noção de cidadania deliberativa dá sentido a essa alternativa decisória.

Como esclarece Tenório (1998; 2005), a cidadania deliberativa encontra-se no centro do debate entre liberais e republicanos: estes focam o que é melhor para o grupo ou a comunidade; aqueles priorizam os compromissos e a liberdade individual para negociar. Buscando retirar o que há de melhor nas duas concepções, no caminho deliberativo, sugerido por Habermas (1995), elege-se como prioridade o consenso válido, garantido por pressupostos comunicativos. Em síntese, nas relações entre sociedade e Estado, a cidadania deliberativa advoga que os indivíduos, conscientes de seu papel de sujeitos sociais, devam atuar não apenas como contribuintes ou eleitores, mas como atores ativos e solidários que decidem o destino de sua comunidade. A participação social, colocada em evidencia nesse ideário, será objeto de discussão dos próximos parágrafos.

Nogueira (2005) expressa em outros termos, voltados à práxis, o embate entre valores liberais e republicanos. Sem o intuito de transcendê-los, como no caso anterior, o autor analisa sua coexistência na esfera pública brasileira e discute com lucidez as contradições da participação contemporânea. Mesmo admitindo múltiplas formas de participação, ele nota que, atualmente, quatro orientações coexistem: assistencialista, corporativa, eleitoral e política. Há, ainda, uma modalidade emergente: a participação gerencial.

A participação assistencialista, de caráter filantrópico ou solidário, é observável em todas as épocas como reflexo da natureza gregária do homem. Iniciativas de auxílio mútuo e mutirão desenvolvem-se cotidianamente para minimizar o infortúnio, otimizar recursos coletivos e solucionar conflitos. Em períodos anteriores à afirmação de direitos, ela representou o tipo hegemônico de participação.

A participação corporativa associa-se à satisfação de demandas particulares de grupos sociais ou classes profissionais. Ela é, portanto, excludente em certa medida. Em nossos dias, sua relevância é impar e proporcional à legitimidade da defesa de interesses.

De outro modo, a participação eleitoral interfere nos rumos de coletividades inteiras. Por meio dela os cidadãos transcendem domínios individuais (direitos civis) e manifestam-se sobre garantias comuns (direitos políticos). Contudo, o envolvimento dos mesmos é limitado ao voto. A participação eleitoral é uma expressão típica do contratualismo liberal.

A participação política supera a eleitoral na medida em que diferenças são explicitadas em campos organizados por leis e instituições visando à partilha do poder. Nela a cidadania é resguardada e fortalecida e os indivíduos distinguem-se não por interesses corporativos, mas por diferentes visões de mundo, alicerçadas em movimentos sociopolíticos. Seu nexo com a cidadania deliberativa é evidente.

As coletividades contemporâneas, plurais e poliárquicas, favorecem a expansão da participação e, ainda, da demanda por participação. Porém, tal engajamento não expressa, necessariamente, os traços da forma política de participação. Para Nogueira (2005), as forças do capitalismo e da sociedade moderna contribuem para o esvaziamento do conteúdo ético-político da participação - em favor de posições mais pragmáticas, voltadas a interesses particulares, a resolução de problemas e a satisfação de demandas pontuais. Assim: 
Há uma espécie de tendência objetiva que força a que a participação deixe de ser pensada como recurso vital para a recriação do social, a fundação de novos Estados ou a instituição de formas mais democráticas e civilizadas de convivência, e passe a ser pensada como um meio para a inversão de prioridades governamentais e a transferência de custos gerenciais. A participação tende a converterse em um instrumento para solidarizar governantes e governados, para aliviar e agilizar a ação governamental, para compartilhar custos e decisões, para reduzir atritos entre governo e sociedade. (NOGUEIRA, 2005, p. 140-141)

A Constituição Federal de 1988 contribuiu para a formação desse quadro ao pregar a descentralização participativa, que se aplicou a campos importantes como saúde, educação, assistência social e regulação urbana. Em síntese, a qualidade e os desdobramentos da participação dependem, em grande medida, de sua conexão a uma esfera ético-política. O engajamento que se dedica a compartilhar decisões governamentais, resguardar direitos pontuais, interferir em elaborações orçamentárias ou prover sustentabilidade a iniciativas públicas volta-se mais à obtenção de resultados e vantagens que à mudança de correlações de força ou padrões de poder. Antes da participação política, Nogueira (2005) identifica nessas práticas uma participação cidadã.

Isso ocorre, pois, ela reflete elementos distintos e, por vezes, contraditórios da dinâmica política, isto é, a intenção de tomar parte em processos sociais visando à promoção de valores e interesses particulares e, também, à garantia cidadã de igualdade e universalidade de direitos, responsabilidades e deveres. A participação contemporânea pode transitar, portanto, do singular ao coletivo, do interesse à ética. Dessa observação, Nogueira (2005) deduz o conceito de participação gerencial:

Sugiro, por isso, que no bojo mesmo dessa modalidade 'cidadã' de participação, está se construindo um outro tipo de participação que se orienta por uma idéia de política como 'troca' entre governantes e governados: quanto mais interações cooperativas existirem, melhor para o sucesso eleitoral e a legitimação dos governantes e melhor para os grupos sociais envolvidos, que podem assim ver atendida parte de suas postulações. Creio ser possivel chamar esse conjunto de práticas e ações de participação gerencial. (NOGUEIRA, 2005, p. 142)

Avançando em seu raciocínio, o autor pontua as possibilidades e, principalmente, os riscos da participação gerencial. Assim, ela possui elementos potenciais de democratização, aproximando-se dos núcleos decisórios e limitando sua elitização. Porém, nesse contexto, a participação pode ser administrada, contida, impedida de se radicalizar e de produzir efeitos incômodos. Os cidadãos podem, portanto, participar sem se envolver demasiadamente nas decisões importantes.

Nogueira (2005) conclui não haver qualquer contradição insanável entre participação política e participação gerencial. São conciliáveis, pois a luta por interesses pode servir à consolidação de agendas democráticas amplas. Ademais, se a participação voltada à garantia de interesses tornar-se acessível ao coletivo e permeável ao desafio da emancipação - rechaçando a manipulação e a subalternidade -, ela será importante para a democracia. A participação gerencial pode, portanto, politizar-se, pensar o todo social e a esfera política em sua pluralidade e complexidade.

Nos conselhos gestores, o risco de a participação gerencial sobrepor-se à participação política existe, principalmente quando: a) os conselheiros não possuem vínculos fortes com organizações sociais; b) as organizações sociais relacionam-se tangencialmente com movimentos populares; c) os movimentos populares não possuem lastro histórico ou comunitário; d) os poderes locais agem estrategicamente para não partilhar poder; e) os poderes locais não consideram os conselhos legítimos ou relevantes; f) os conselheiros desconhecem os sistemas de políticas sociais, a máquina pública e os meios para viabilizar suas decisões; e g) processos de 'empoderamento' de conselheiros são negligenciados.

Os três primeiros pontos operam para a fragilidade do controle social sobre as atividades dos conselhos. Nesse sentido, representantes e representados devem tomar consciência dos dilemas da participação cidadã, que oscila entre as formas política e gerencial. Devem perceber, ainda, o maior potencial da primeira em superar os vícios históricos da relação sociedade-Estado no Brasil. 


\section{Democracia deliberativa e conselhos: condições interinstitucionais de efetividade}

As condições interinstitucionais de efetividade dos conselhos gestores enquanto instrumentos da democracia deliberativa vinculam-se ao seu relacionamento com segmentos sociais (entidades focadas em demandas coletivas, associações comunitárias, movimentos populares, organizações não governamentais etc.) e poderes locais (o executivo local e suas secretarias, o legislativo e o ministério público). Associam-se, também, à sua capacidade de atuação como esferas públicas.

Ao interagir nos conselhos, a sociedade pode favorecer a transparência das ações governamentais, a mudança de práticas e concepções e, ainda, a coerência e a viabilidade de programas públicos. Em contraste, ela pode se revelar um interlocutor passivo, desarticulado e útil à legitimação de atos e discursos. A participação social é um tema recorrente nas pesquisas sobre conselhos gestores. Nesse sentido, Gohn (2001, p. 95) aponta a necessidade de definições mais precisas para o conceito, entendendo-o como “(...) o processo mediante o qual as diferentes camadas sociais da população têm acesso aos espaços de definir e avaliar as políticas públicas, especialmente as de caráter social”. Esta autora argumenta que mobilizações efetivas são qualificadas: os atores sociais compreendem o funcionamento de estruturas e rotinas estatais. Disso depende o exercício da cidadania ativa, não regulada.

Além desse aspecto, o vigor do engajamento social em conselhos tem sido associado ao nível de contestação pública manifesto - poliarquia (PERISSINOTTO, 2002) -; à posse de recursos individuais e coletivos, convencionais e não convencionais (FUKS, 2002); aos valores específicos de cada segmento de política pública, ao desenho institucional dos órgãos e à natureza das relações entre governo local e população (FUKS; PERISSINOTTO, 2006); ao padrão de organização dos movimentos populares a que se ligam os conselheiros e à posição ideológica dos gestores públicos ante a participação (CÔRTES, 2002).

Dando segmento à discussão, os conselhos gestores são arranjos institucionais peculiares, a concretização e a continuidade de suas decisões dependem de suas conexões com os poderes locais. Nos próximos parágrafos são discutidas, de modo breve, essas relações.

As políticas públicas expressam intenções de governo, comunicadas à sociedade e ratificadas por ela em processos eleitorais, que buscam contemplar demandas coletivas e assegurar direitos estabelecidos (CHRISPINO, 2005). Nesse sentido, sob a ótica do executivo local, os conselhos deveriam representar fontes relevantes de informações, percepções e soluções. Contudo, esse potencial é habitualmente subestimado: muitos órgãos não conseguem viabilizar suas ideias e deliberações. Já outros são completamente destituídos de sentido, autonomia e recursos.

Normalmente, decisões importantes dos conselhos gestores excedem seus limites e encontram dificuldades para se perpetuarem. Assim, o diálogo dos órgãos com o poder legislativo pode transformar ideias e resoluções em leis municipais. Tal processo tende a ampliar as discussões sobre o objeto de deliberação, aprimorando-o.

A Constituição de 1988 define o ministério público como órgão fiscalizador dos poderes instituídos. Ele deve, portanto, intermediar de modo autônomo as demandas dos cidadãos com o executivo, o legislativo e o judiciário (FRISCHEISEN, 2000). O ministério público pode converter-se em um aliado dos conselhos, zelando pelos desdobramentos de suas decisões. Pode, também, viabilizar o controle social sobre os próprios conselhos.

Em síntese, o diálogo entre conselhos gestores e poderes locais é essencial à democratização de políticas sociais e deve gozar de efetiva reciprocidade. Deve, ainda, encontrar no interesse público sua orientação fundamental. Entretanto, as relações conselho-sociedade e conselho-poderes são limitadas, respectivamente, pelas culturas cívica e política nacionais. A primeira traduz-se em desarticulação social, minando a representatividade dos órgãos. A segunda, marcada pela inércia do autoritarismo, do patrimonialismo e do clientelismo, reforça a resistência dos governos em partilhar poder decisório, em acatar deliberações contrárias à sua vontade, em publicizar suas ações e em permitir a livre designação da representação social (TEIXEIRA, 2000b). 
Tais obstáculos não devem intimidar esforços voltados à transformação dos conselhos em esferas públicas propícias à argumentação cidadã e aptas a aglutinar, lapidar e comunicar demandas coletivas - conquistando, assim, relevância e legitimidade diante da sociedade e dos poderes locais.

\section{Considerações finais}

O envolvimento dos cidadãos em rotinas democráticas, ou seja, na seleção de representantes políticos e na formulação de decisões de grande amplitude, foi promovido quantitativamente pela universalização do voto consolidando, assim, a democracia representativa. Avanços qualitativos nesse processo foram assegurados por meio da sedimentação de características da democracia participativa (como a interlocução entre sociedade e Estado e a ampliação da relevância persuasiva da opinião pública) e da democracia deliberativa (como a função norteadora do debate social diante do agir político e o reconhecimento do papel da argumentação pública em decisões coletivas).

Embora marcados por contradições, os avanços qualitativos concentram esforços teóricos e empíricos de construção política e institucional. Destaca-se, entre os primeiros, o questionamento da visão de que a legitimidade das ações públicas deriva necessariamente da vontade da maioria. Ressalta-se, entre os demais, a criação de domínios públicos não estatais propícios ao confronto e à síntese de ideias.

Os conselhos gestores de políticas públicas despontam entre tais espaços. Isso ocorre devido ao seu desenho institucional (que busca resguardar a simetria decisória entre sociedade e Estado), ao seu caráter deliberativo e ao seu nível de inserção nos municípios brasileiros. Contudo, sua atuação não é garantia de um novo padrão de relações entre população e governo. Ao contrário, pode aumentar as evidências do formalismo na esfera pública brasileira, na qual a norma, o discurso e a prática são desarticulados.

De modo a discutir o alinhamento entre democracia deliberativa e conselhos gestores, o ensaio apresentou condições de efetividade destes. Assim, em sua dimensão formal, sua natureza deliberativa e paritária, seus mandatos, seus processos pedagógicos e seu acesso a recursos foram detalhados. Como elementos substantivos, ligados à sua dinâmica deliberativa, foram destacados o respeito ao posicionamento das partes, as formas de manifestação de saberes especializados, o controle de pautas, a promoção da cidadania deliberativa e o fomento à participação política em detrimento da participação gerencial. Condições interinstitucionais de efetividade foram, por fim, pontuadas, com ênfase nas relações dos conselhos gestores com a sociedade civil organizada e com os poderes locais instituídos.

Obviamente, não se procurou esgotar, no texto, os pressupostos de efetividade dos conselhos. Nesse sentido, alguns pontos ficaram por discutir ou foram tratados tangencialmente. Ainda assim, acredita-se que o ensaio foi capaz de organizar os elementos presentes na interface entre democracia deliberativa e conselhos gestores esboçando uma agenda de pesquisa em nível local e evidenciando limites e possibilidades desses arranjos institucionais. 


\section{Referências}

ARON, R. As etapas do pensamento sociológico. São Paulo: Martins Fontes, 2002.

AVRITZER, L. Teoria democrática e deliberação pública. Lua Nova, n. 50, p. 25-46, 2000.

Sociedade civil e participação social no Brasil. Disponível em <http://www.democraciaparticipativa.org>. Acesso em: 05 dez. 2006.

BELLAMY, R. Liberalismo e sociedade moderna. São Paulo: Editora UNESP, 1994.

BOBBIO, N. Liberalismo e democracia. São Paulo: Brasiliense, 1994.

BOBBIO, N.; MATTEUCCI, N.; PASQUINO, G. Dicionário de política. Brasília: Editora UnB: Linha Gráfica Editora, 1991.

BRESSER PEREIRA, L. C. Democracia republicana e participativa. Novos estudos CEBRAP, São Paulo, v. 71, p. 77-91, mar. 2005.

CHRISPINO, A. Binóculo ou luneta: os conceitos de política pública e ideologia e seus impactos na educação. Revista Brasileira de Política e Administração da Educação. São Bernardo do Campo, v. 21, n. 1, 2005.

CÔRTES, S. M. V. Construindo a possibilidade da participação dos usuários: conselhos e conferências no Sistema Único de Saúde. Sociologias, Porto Alegre, v. 7, p. 18-49, 2002.

DAHL, R. A. Sobre a democracia. Brasília: EdUnB, 2001.

FARIA, C. F. Democracia deliberativa: Habermas, Cohen e Bohman. Lua Nova, São Paulo, v. 49, p. 47-67, 2000.

FRISCHEISEN, L. C. O Ministério Público como garantia da efetividade dos conselhos. In: CARVALHO, M. C. A. A.; TEIXEIRA, A. C. C. (Orgs.). Conselhos gestores de políticas públicas. São Paulo: Pólis, 2000.

FUKS, M. Participação política em conselhos gestores de políticas sociais no Paraná. In: ENCONTRO DA ASSOCIAÇÃO BRASILEIRA DE CIÊNCIA POLÍTICA, 3, Niterói. Anais..., 2002.

FUKS, M.; PERISSINOTTO, R. M. Recursos, decisão e poder: os conselhos gestores de Curitiba. Revista Brasileira de Ciências Sociais, São Paulo, v. 21, n. 60, p. 67-82, 2006.

GOHN, M. G. Conselhos gestores e participação sócio-política. São Paulo: Cortez, 2001.

HABERMAS, J. Três modelos normativos de democracia. Lua Nova, São Paulo, v. 36, p. 40-53, 1995.

HIRST, P. A democracia representativa e seus limites. Rio de Janeiro: Jorge Zahar, 1992.

INSTITUTO BRASILEIRO DE GEOGRAFIA E ESTATíSTICA. Perfil dos municípios brasileiros. Pesquisa de informações básicas municipais, 1999. Rio de Janeiro: Departamento de população e indicadores Sociais, 2001.

LÜCHMANN, L. H. H. Possibilidades e limites da democracia deliberativa: a experiência do orçamento participativo de Porto Alegre. 2002. 226 p. Tese (Doutorado em Ciência Política) - IFCH, Universidade Estadual de Campinas, Campinas, 2002.

MACPHERSON, C. B. A democracia liberal: origens e evolução. Rio de Janeiro: Zahar Editores, 1978.

NOGUEIRA, M. A. Um Estado para a sociedade civil: temas éticos e políticos da gestão democrática. São Paulo: Cortez, 2005.

NORONHA, R. Avaliação comparativa dos conselhos municipais. In: CARVALHO, M. C. A. A.; TEIXEIRA, A. C. C. (Orgs.). Conselhos gestores de políticas públicas. São Paulo: Pólis, p. 83-86, 2000.

PATEMAN, C. Participação e teoria democrática. Rio de Janeiro: Paz e Terra, 1992.

PERISSINOTTO, R. M. Participação e democracia: o caso dos conselhos de assistência social de Curitiba. In: ENCONTRO DA ASSOCIAÇÃO BRASILEIRA DE CIÊNCIA POLÍTICA, 3., 2002, Niterói. Anais...2002.

RIBEIRO, A. C. T.; GRAZIA, G. Experiência de orçamento participativo no Brasil (1997-2000). Petrópolis: Vozes / Fórum Nacional de Participação Popular, 2003.

SILVA, B.; MIRANDA NETTO, A. G. (Coord.). Dicionário de ciências sociais. 2. ed. Rio de Janeiro: Fundação Getulio Vargas, 1987. 
TEIXEIRA, E. C. Efetividade e eficácia dos conselhos. In: CARVALHO, M. C. A. A.; TEIXEIRA, A. C. C. (Orgs.). Conselhos gestores de políticas públicas. São Paulo: Pólis, p. 92-96, 2000a.

. Conselhos de políticas públicas: efetivamente uma nova institucionalidade participativa? In: CARVALHO, M. C. A. A.; TEIXEIRA, A. C. C. (Orgs.). Conselhos gestores de políticas públicas. São Paulo: Pólis, p. 97-119, 2000b.

TENÓRIO, F. G. Gestão social: uma perspectiva conceitual. Revista de administração pública, v. 32, n. 5, p. 7-23, 1998.

TENÓRIO, F. G., (Re)visitando o conceito de gestão social. In: LIANZA, S.; ADDOR, F. Tecnologia e desenvolvimento social e solidário. Porto Alegre: UFRGS, p. 151-171, 2005.

TOCQUEVILLE, A. Democracia na América. São Paulo: Companhia editora nacional, 1969.

TOURAINE, A. O que é a democracia? Petrópolis: Vozes, 1996.

VITULLO, G. O. Desafio da construção de um modelo democrático deliberativo. Sociologias, Porto Alegre, v. 2, n. 3, p. 186-231, jan./jun., 2000. 